УДК 130.2

DOI 10.52575/2712-746X-2021-46-3-481-488

\title{
Литературно-эстетическая \\ и философская рефлексия А.А. Фета: взгляд из XXI века
}

\author{
Липич Т.И., Липич В.В. \\ Белгородский государственный национальный исследовательский университет, \\ Россия, 308015, г. Белгород, ул. Победы, 85 \\ E-mail: lipich@bsu.edu.ru;lipich_v@bsu.edu.ru
}

\begin{abstract}
Аннотация. Статья посвящена художественной рефлексии А.А. Фета в контексте творческого взаимодействия поэта с романтической традицией своей эпохой. Авторы исследуют проблему литературно-философской рефлексии и анализируют специфику фетовского поэтического феномена. С опорой на сравнительно-исторический принцип познания, а также философскоантропологический и философско-культурологический подходы проанализирована динамика критических оценок и откликов современных поэту критиков, рассматривавших поэзию А. Фета. Сделан вывод о необходимости преодоления неоправданного исследовательского равнодушия к творческому наследию А. Фета и важности исследовательских стремлений, направленных на осмысление своеобразия его поэзии.
\end{abstract}

Ключевые слова: творчество, литературно-философский романтизм, лирика, двоемирие, эстетка, поэтическое вдохновение, рефлексия, самобытность, лирический герой, субъективность, мироотношение.

Для цитирования: Липич Т.И., Липич В.В. 2021. Литературно-эстетическая и философская рефлексия А.А. Фета: взгляд из XXI века. NOMOTHETIKA: Философия. Социология. Право, 46 (3): 481-488. DOI: 10.52575/2712-746X-2021-46-3-481-488

\section{Literary-aesthetic and Philosophical Reflection of A.A. Fet: A View from the 21th Century}

\author{
Tamara I. Lipich, Vasiliy V. Lipich \\ Belgorod National Research University, \\ 85 Pobedy St, Belgorod, 308015, Russia \\ E-mail: lipich@bsu.edu.ru; lipich_v@bsu.edu.ru
}

\begin{abstract}
The article is devoted to the artistic reflection of A. A. Fet in the context of the poet's creative interaction with the romantic tradition of his era. The authors investigate the problem of literary and philosophical reflection and analyze the specifics of the Fetov poetic phenomenon. Based on the comparativehistorical principle of cognition, as well as philosophical-anthropological and philosophical-cultural approaches, the dynamics of critical assessments and responses of contemporary critics who considered the poetry of A. Fet is analyzed. The conclusion is made about the need to overcome the unjustified research indifference to the creative heritage of A. Fet and the importance of research aspirations aimed at understanding the originality of his poetry.
\end{abstract}

Keywords: creativity, literary and philosophical romanticism, lyrics, duality, esthete, poetic inspiration, reflection, originality, lyrical hero, subjectivity, world attitude

For citation: Lipich T.I., Lipich V.V. 2021. Literary-aesthetic and Philosophical Reflection of A.A. Fet: A View from the 21th Century. NOMOTHETIKA: Philosophy. Sociology. Law series, 46 (3): 481-488 (in Russian). DOI: 10.52575/2712-746X-2021-46-3-481-488 
Совсем недавно культурное сообщество страны отметило 200 -летие со дня рождения замечательного русского поэта и прозаика А.А. Фета. Первое знакомство с творчеством этого удивительного и тонкого мастера слова происходит у нас еще в юности, в школьные годы, и его проникновенные строки остаются в памяти на всю жизнь:

Я пришел к тебе с приветом,

Рассказать, что солнце встало,

Что оно горячим светом

По листам затрепетало ${ }^{1}$.

или:

На заре ты ее не буди,

На заре она сладко так спит;

Утро дышит у ней на груди,

Ярко пышет на ямках ланит².

Его стихи - романтически-трогательное и воздушное прикосновение к миру. Примеров этому в поэзии А. Фета можно найти немало. Многие известные русские композиторы считали за честь переложить его стихи на музыку, благодаря чему наша музыкальная культура имеет в своей сокровищнице романсы удивительной чистоты и свежести.

Как поэт-лирик, переводчик, мемуарист А. Фет интересовал не только своих современников, но и исследователей более поздних периодов, поэтому до сих пор не прекращаются споры об этой достаточно таинственной и загадочной личности. Сегодня литературная репутация творчества Фета как представителя «эстетического» направления часто сводится к реализации автором идеи «чистого искусства». Достаточно вспомнить современных авторов, занимающихся исследованием творчества А. Фета, например: В.А. Шеншина [2011], В.А. Кошелева [2011], В.И. Коровина [2021], С.Я. Левит [2020], И.С. Пигулевскую [2020].

Одним из первых современных поэту критиков, обративших внимание на творчество А. Фета, был Н. Кудрявцев, профессор Московского университета, который, исходя из традиционных для того времени эстетических принципов непреднамеренности поэтического творчества, писал: «Песня складывается прежде, чем поэт думал о ней, она сама собою сливается у него с губ...» [Кудрявцев, 1850a, с. 9]. Талант Фета, по мнению критика, лежит у поэта в груди, «словно в какой-то бессознательности и нисколько не зависит ни от воли, ни от мысли его» [Кудрявцев, 1850a, с. 2].

Многие из современников сравнивали поэтическое творчество Фета с философской поэзией Гете, Гейне, сопоставляли с Пушкиным и Жуковским. Так, известный критик тогдашней эпохи А. Григорьев писал: «Самобытность и даже резкая самобытность составляет, если хотите, недостаток этого таланта, по крайней мере, в глазах многих... соприкасаясь всему и ни с чем не роднясь глубоко, без определенной тенденции, кроме тенденции художника, это дарование стоит как-то уединенно, как-то отдельно в нашей литературе» [Григорьев, 1850, с. 53]. Вместе с тем критик, выделяя художественно-эстетические особенности поэзии А. Фета, отмечал «способность сообщать осязаемость тонким, неопределенным, для других неподмеченым впечатлениям» [Григорьев, 1850, с. 55], а также необыкновенную пластичность и ясность лирической формы Фета. Позже в своих критических статьях А. Григорьев называл поэзию А. Фета «болезненной поэзией», потому что «это поэзия углубленного анализа мира человека, анализа, отличающегося отсутствием

${ }^{1}$ Фет А.А. 1978. Стихотворения. Проза. Воронеж, Центрально-Черноземное книжное издательство, с. 63

${ }^{2}$ Там же, с. 46. 
типичности и преобладанием особенности и случайности в выражении, доходящих до неясности и причудливого уродства» [Григорьев, 1850, с. 72].

Нельзя не сказать и об отношении к творчеству А. Фета таких собратьев по творческому цеху, как И.С. Тургенев, Н.А. Добролюбов, позже Ф.М. Достоевский, М.Е. Сатыков-Щедрин и других. Их постоянные споры о правах «разума» и «вдохновения» выливались в острый спор о творческом методе, который в конечном счете, по мнению исследователя Б.Я. Бухштаба, мог быть назван «импрессионизмом [1990, с. 60]. Упомянутые современники порицали А. Фета за неопределенность, неясность, расплывчатость его поэтических образов, за взаимопереплетение оттенков, красок, звуков. В этом смысле Фет выступает прямым предшественником декадентов, символистов. Как справедливо отмечает Д.Д. Благой, «уже почти с самого начала, с сороковых годов, романтизм Фета - его поэзия, способная улавливать... неуловимо музыкальные впечатления, зыбкие душевные движения в них, как и в природе, окружающей человека, "трепете", "дрожи", живой динамике переливов красок и звуков, "волшебных изменений милого лица", "непрестанных колебаниях", "переходах, оттенках", диалогическом сочетании противоположностей - был окрашен чертами, которые значительно позднее получили название "импрессиононизм"» [Благой, 1975, с. 107].

Тесное переплетение философии и литературы в творчестве Фета увидел и его «литературный советчик» Н.Н. Страхов, который в своих работах, посвященных анализу творчества А. Фета («Юбилей поэзии Фета», «Несколько слов памяти Фета» и др.), отмечал удивительную свежесть и «незаношенность» его стихов. В этих статьях критик называл лирику Фета «пробным камнем для способности понимать поэзию» [Страхов, 1912, T. I, c. 14].

Для понимания и уяснения отношения Фета к Н.Н. Страхову приведем слова из его письма, отправленного в ноябре 1877 г., в котором поэт, в частности, пишет: «Не буду говорить, до какой степени, после мимолетной встречи в Питере, меня тянуло сблизиться с Вами как с мыслителем. В нашей умственной пустыне такое влечение более чем понятно; но, увидав Вас ближе, я открыл в Вас то, что для меня едва ли не дороже мыслителя» ${ }^{1}$.

Н. Страхов отвечал ему дружеской взаимностью. Анализируя творчество А. Фета, философ постоянно подчеркивал связь его поэзии с будничными событиями и явлениями жизни, которые пробуждают возвышенные настроения и впечатления. Н. Страхов отмечает удивительную особенность А. Фета видеть со стороны «разлитую в нас самих» действительность» с позиций красоты. Он писал: «Его стихи - как будто внезапная молния поэтического озарения действительности» [Страхов, 2000, с. 425].

В этой связи можно привести слова Д.Д. Благого, который, сравнивая поэзию Пушкина и Фета, писал: «Романтическая по пафосу и по методу, лирика Фета вместе с тем сродни пушкинской "поэзии действительности", представляет своеобразный романтический ее вариант. Только говоря о Пушкине, в этом словосочетании логическое ударение следует ставить на каждом из этих двух слов, говоря о Фете - на первом из них» [Благой, 1975 , с. 55].

Уже после смерти поэта Н.Н. Страхов пытался отбивать атаки и утверждения критиков, что поэзия Фета противостоит действительности. В некрологе «Несколько слов памяти Фета» критик писал следующее: «Он хотел только со всею резкостию выразить, до какой степени поэзия преобразует действительность, возводит ее в "перл создания"; как истый лирик, он хотел научить нас, что внешний мир есть только повод к поэзии, что она коренится и растет лишь в нашем внутреннем мире» [Страхов, 2000, с. 427]. И здесь Страхов солидарен с мнением других критиков, отмечавших связь поэзии Фета с гегелевским пониманием творчества.

${ }^{1}$ Фет А.А. 1982. Сочинения: в 2-х т. Т. 1. М., Художественная литература, с. 79. 
Так, некоторые из них - С.П. Шевырев [1844], А. Григорьев [1988], В.П. Боткин [1982] - сравнивали поэзию А. Фета с теорией лирической поэзии Гегеля, которая «развивается из принципа субъективности, вынужденной извлекать и оформлять субстанциальный и объективный элемент, как нечто ей принадлежащее, причем, она все более и более осознает эту субъективную внутри себя сосредоточенность» [Гегель, 1958, т. 14, с. 297].

Другой современник А. Фета - В. Соловьев также разделял точку зрения на его творчество, как творчество в духе символизма, в духе «чистого искусства», так как корни его поэзии «темны, бледны и бесформенны» [Соловьев, 1990, с. 217] и отражаются в «беспредметных» стихах, в которых очень тонко фиксируются различные оттенки и нюансы человеческих отношений, а также душевные порывы.

Особый интерес представляют противоположные вышеназванным трактовки творчества А. Фета другого его современника А.В. Дружинина, который, с одной стороны, соглашался с оценкой запутанности и темности его стихов, а с другой - считал, что автор «умеет забираться в сокровенные тайники души человеческой. Область его не велика, но в ней он полный властелин» [Дружинин, 1983, с. 89].

Дружинин также отмечал, что поэт видел поэтическое в самых простых вещах, он отмечал особенно его пейзажную лирику. Вместе с тем, сравнивая талант А. Фета с талантом А.С. Пушкина и М.Ю. Лермонтова, другой критик - Боткин В.П. отмечал, что «крайней несправедливостью было бы требовать от него не того, что дает и что может дать талант его, тем более, что в нем есть свойства и достоинства, бесценные для истинных любителей поэзии» [Боткин, 1984, с. 213].

Уже в ХХ веке В.Я. Брюсов, читая лекцию о творчестве А. Фета в Московском литературно-художественном кружке, отмечал, что все творчество поэта - это «экстатическое прозрение», «сверхчувственная интуиция», это призыв к настоящей жизни.

Можно сказать, что так или иначе, но поэзия А. Фета волновала многие умы ХХ века. В их числе - Ю. Айхенвальд [1908], А. Архангельский [2001], Б.Я. Бухштаб [2000], Е.А. Маймин [1989] и многие другие литературные критики и исследователи. Необходимо также отметить, что ряд исследователей - Б.В. Никольский [1894], А. Белый [1994], Г.П. Козубовская [1994], - говоря о романтической компоненте поэзии Фета, считают его творчество переходным периодом от романтизма к символизму. И действительно, на наш взгляд, литературно-философский романтизм А. Фета, сложившийся еще во времена В. Жуковского, явился тем связующим звеном, который соединил две эпохи: эпоху А.С. Пушкина и эпоху А.А. Блока.

Своеобразным этапом постижения творчества Фета можно считать и оценки, данные Б.Н. Никольским, известным в конце XIX - начале XХвека пушкинистом. В статье «Основные элементы лирики Фета» он детально и тонко анализировал творчество поэта [Никольский, 1912 a, б]. В качестве особенных характеристик поэзии Фета исследователь отмечал легкость, прозрачность, неуловимость, некоторую туманность. И, что очень важно, он увидел удивительную связь философских и поэтических смыслов в творчестве Фета. Б.Н. Никольский характеризовал творчество поэта как «золотой мост между философией и поэзией» [Никольский, 1912б, т. 2, с. 29]. В частности, ученый определил место поздней философской лирики поэта между Пушкиным и Тютчевым. Он характеризовал поэзию Фета как пантеистическую, но Фет улавливал настроение природы и показывал гармонию человека и природного мира без той болезненности мировосприятия, которая была свойственна Тютчеву.

Если для Тютчева человек является «грезой природы», то для Фета - природа выступает как «мимолетный сон», и поэтому только ночью человек может полнее слиться с 
природой. В фетовском космосе природа приобретает красоту-грезу, при помощи которой у человека появляется возможность забыть о тех страданиях, которые она, природа, приему носит. Это дает возможность погрузиться в созерцание ее творческого великолепия. Благодаря этому, человек видит в природе высший смысл и высшую мудрость. Человек не отделен от природы, составляет с ней единство, он слит с ней в полном восторге и испытывает чувства красоты, величия и жизненности Вселенной, космоса, с которыми он слит воедино. Так, в стихотворении «Заря прощается с землею» ${ }^{1}$ Фет проводит романтическую мысль о «жизни двойной», которую чувствует вся природа и человек, погружаясь во мглу вместе с нею, - то есть налицо романтическое видение мира.

Особо хотелось бы отметить А. Фета как певца любви, которой он придает универсальное значение. Вслед за И.С. Тургеневым, провозгласившим: «Только ею, только любовью держится и движется жизнь» ${ }^{2}$ [Тургенев И. С.1956, с. 474], Фет обозначает любовь «центром, на который навивается всякая поэтическая нить» [Бухштаб, 1990, с. 89].

Фетовская романтическая поэзия любви сочетает полную гамму противоречивых, доходящих до противоположностей, чувств. Любовь, отмечает поэт, это такое чувство, перед которым даже смерть бессильна. Любовь у Фета приобретает особую благоуханность, «ароматичность». В лирике А. Фета символом любви становится образ соловья, который поет в ликующем гимне. Вспомним стихотворение «Соловей и роза» ${ }^{3}$ :

Зацелую тебя, закачаю

Но боюсь над тобой задремать.

На заре лишь уснешь ты; я знаю

Что всю ночь будешь петь ты опять.

Мелодия любви звучит в лирике Фета, словно «переливаясь» из одного стихотворения в другое, фоном для которых становится лунный свет, звездное небо, музыка:

Сияла ночь. Луной был полон сад. Лежали

Лучи у наших ног в гостиной без огней.

Рояль был весь раскрыт, и струны в нем дрожали,

Как и сердца у нас за песнею твоей ${ }^{4}$.

Но постепенно от свежести и «лирической дерзости» у Фета прорисовывается чувство трагичности любви. Вероятно, это связано было и с некоторыми событиями в личной жизни поэта. Его трагическая любовь к Марии Лазич закончилась гибелью девушки. И даже спустя 40 лет после ее смерти, стихи поэта пронизаны верностью к своей возлюбленной: «Нет, я не изменил. До старости глубокой // Я тот же преданный, я раб твоей любви...» ${ }^{5}$.

И совершенно точен в своих оценках Я. Полонский [1899], писавший, что А. Фет всем своим творчеством не сопротивлялся судьбе и оставался всегда убежденным в своем призвании «чистого лирика».

${ }^{1}$ Фет А.А. 1978. Стихотворения. Проза. Воронеж, Центрально-Черноземное книжное издательство, с. 63

${ }^{2}$ Тургенев И.С. 1956. Собрания сочинений: в 12 т. Т. 8. М., Госполитиздат, 474 с.

${ }^{3}$ Фет А.А. 1982. Сочинения: в 2-х тт. Т. 1. М., Художественная литература, с. 79.

${ }^{4}$ Там же, с. 130.

${ }^{5}$ Там же, с. 68. 


\section{Заключение}

Наступивший XXI век развенчал многие идеалы двух предыдущих веков, охладев к прежним кумирам, «властителям дум» и душ. В условиях бесконечного и не во всем успешного реформирования в сфере образования, переоценке «старого», пересмотра прежних аксиологических констант, разрушения заслуженных авторитетов, в условиях, как выразился Н. Бердяев, «расщепления человека» меняется отношение и к слову, и к художникам слова. В произошедшей переоценке некогда незыблемых ценностей, смене политических и нравственных ориентиров, тотальной коммерциализации стратегий и пресловутого бизнес-мышления изменилось и отношение общества к такому неподражаемо проникновенному лирику, как А.А. Фет. Увы, и не только к нему одному! Целый ряд великих русских поэтов и прозаиков становятся «непрочитанной гордостью» современного молодого человека. Очень жаль...

\section{Список литературы}

1. Айхенвальд Ю. 1908. Силуэты русских писателей. Вып. 2. М., Научное слово, 166 с.

2. Архангельский А. 2001. Для звуков сладких и молитв. Афанасий Афанасьевич Фет (1820-1892). Литература, 24: 5-8.

3. Белый А. 1994. Символизм как миропонимание. М., Республика, 395 с.

4. Благой Д.Д. 1975. Мир как красота. О «Вечерних огнях» А. Фета. М., Художественная литература, $110 \mathrm{c}$. $320 \mathrm{c}$.

5. Боткин В.П. 1984. Литературная критика: Публицистика: Письма. М., Советская Россия,

6. Боткин В.П. 1982. Русская эстетика и критика 40-50-х годов XIX века. М., Искусство, $487 \mathrm{c}$.

7. Бухштаб Б.Я. 1990. Фет: очерки жизни и творчества. Л., Наука, 138 с.

8. Бухштаб Б.Я. 2000. Фет и другие. Избранные работы. СПб., Академический проект, 560 с.

9. Гегель Г.Ф. 1958. Сочинения: в 14 т. Т. 14. М., Государственное социальноэкономическое издательство «Полиграфкнига», 440 с.

10. Григорьев А.А. 1850. Отечественные записки. Том 68. М., тип. Н. Степанова, 162 с.

11. Григорьев Ап. 1988. Мои литературные и нравственные скитальчества. М., Наука, 237 с.

12. Дружинин А.В. 1983. Литературная критика. М., Советская Россия, 384 с.

13. Козубовская Г.П. 1994. А.А. Фет и проблема мифологизма в русской поэзии XIX начала XX века. Дисс. ... д. филол. н. СПб, 345.

14. Коровин В.JI. Афанасий Афанасьевич Фет (1820-1892): очерк жизни и творчества. URL: https://www.portal-slovo.ru/philology/37127.php?ELEMENT_ID=37127\&SHOWALL_1=1 (дата обращения: 10 марта 2021).

15. Кошелев В.А. 2011. О месте Фета в истории русской культуры и о его новом собрании сочинений. Литературоведческий журнал, 30: 18-47.

16. Кудрявцев Н. 1850а. Русские второстепенные поэты. А. Фет. Современник, 3. (отд. VI): 4-22.

17. Кудрявцев Н. 1850б. Стихотворения А. Фета. Современник, 3 (отд. V): 161-210.

18. Левит С.Я. 2020. Поэтическая философия Ф.И. Тютчева. Вестник культурологии, 1 (92): $162-175$.

19. Маймин Е.А. 1989. Афанасий Афанасьевич Фет. М., Просвещение, 302 с.

20. Никольский Б.В. 1912. Основные элементы лирики Фета. В кн.: А.А. Фет. Полное собрание стихотворений. Т. 1. СПб., Издание А.Ф. Маркса, 603 с.

21. Никольский Б.В. 1894. Поэт философов. Русское обозрение, 12: 1102-1104.

22. Пигулевская И.С. 2020. Фет Афанасий Афанасьевич. М., Центрполиграф, 220 с.

23. Полонский Я.П. 1899. Философские течения русской поэзии. Изд. 2. СПб., Тип. М. Меркушева. 384 с.

24. Соловьев В.С. 1990. Стихотворения. Эстетика. Литературная критика. М., Книга, 574 с. 
25. Страхов Н.Н. 1912. Юбилей поэзии Фета. В кн.: А.А. Фет. Полное собрание стихотворений. Т. 1. СПб., Издание А.Ф. Маркса, 603 с.

26. Страхов Н.Н. 2000. Литературная критика. СПб., Искусство, 464 с.

27. Шевырев С.П. 1844. Перевод из Горация г. А. Фета. Москвитянин, 1 (I): 27 с.

28. Шеншина В.А. 2011. Изучение жизни и творчества Фета на современном этапе. Литературоведческий журнал, 30: 5-17.

\section{References}

1. Aykhenval'd Yu. 1908. Siluety russkikh pisateley. Vyp. 2. [Silhouettes of Russian writers. Issue 2.]. Moscow, Publ. Nauchnoye slovo, 166 p.

2. Arkhangelsky A. 2001. Dlya zvukov sladkikh i molitv. Afanasiy Afanas'yevich Fet (18201892). [For sweet sounds and prayers. Afanasy Afanasyevich Fet (1820-1892)]. Literatura, 24: 5-8.

3. Bely A. 1994. Simvolizm kak miroponimaniye. [Symbolism as a world view]. Moscow, Publ. Respublika, $395 \mathrm{p}$.

4. Blagoy D.D. 1975. Mir kak krasota. O "Vechernikh ognyakh" A. Feta. [The world as beauty. About "Evening Lights" A. Fet]. Moscow, Publ. Khudozhestvennaya literatura, 110 p.

5. Botkin V.P. 1984. Literaturnaya kritika: Publitsistika: Pis'ma. [Literary criticism: Journalism: Letters]. Moscow, Publ. Soviet Russia, 320 p.

6. Botkin V.P. 1982. Russkaya estetika i kritika 40-50-kh godov XIX veka. [Russian aesthetics and criticism of the 40-50s of the XIX century.]. Moscow, Publ. Iskusstvo, 487p.

7. Bukhstab B.Ya. 1990. Fet: ocherki zhizni i tvorchestva. [Fet: sketches of life and work]. Leningrad, Publ. Nauka, 138 p.

8. Bukhstab B.Ya. 2000. Fet i drugiye. Izbrannyye raboty. [Fet and others. Selected works]. St. Petersburg, Publ. Akademicheskiy proyekt, 560 p.

9. Gegel' G.F. 1958. Sochineniya. [Works]. Vol. 14. Moscow, Publ. State socio-economic publishing house "Poligrafkniga", $440 \mathrm{p}$.

10. Grigoriev A.A. 1850. Otechestvennyye zapiski. [Domestic notes]. Vol. 68. Moscow, Printing house of N. Stepanov, 162 p.

11. Grigor'yev Ap. 1988. Moi literaturnyye i nravstvennyye skital'chestva. [My literary and moral wanderings]. Moscow, Publ. Nauka, 237 p.

12. Druzhinin A.V. 1983. Literaturnaya kritika. [Literary Criticism]. Moscow, Publ. Sov. Russia, $384 \mathrm{p}$.

13. Kozubovskaya G.P. 1994. A.A. Fet i problema mifologizma v russkoy poezii XIX - nachala XX veka. [A.A. Fet and the problem of mythologism in Russian poetry of the XIX - early XX century.] Dis. D. philol. n. St. Petersburg, 345 p.

14. Korovin V.L. Afanasiy Afanas'yevich Fet (1820-1892): ocherk zhizni i tvorchestva. [Afanasy Afanasyevich Fet (1820-1892): an essay on life and creativity]. URL: https://www.portalslovo.ru/philology/37127.php?ELEMENT_ID=37127\&SHOWALL_1=1 (accessed: 10 March 2021).

15. Koshelev V.A. 2011. O meste Feta $v$ istorii russkoy kul'tury i o yego novom sobranii sochineniy. [About Fet's place in the history of Russian culture and about his new collected works]. Literaturovedcheskiy zhurnal, 30: 18-47.

16. Kudryavtsev N. 1850a. Russkiye vtorostepennyye poety. A. Fet. [Russian minor poets. A. Fet]. Sovremennik, 3. (vol. VI): 4-22.

17. Kudryavtsev N. 1850b. Stikhotvoreniya A. Feta. [Poems by A. Fet]. Sovremennik, 3 (vol. VI): $161-210$.

18. Levit S. Ya. 2020. Poeticheskaya filosofiya F.I. Tyutcheva. [Poetic philosophy of F.I. Tyutchev]. Vestnik kul'turologii, 1 (92): 162-175.

19. Maymin E.A. 1989. Afanasiy Afanas'yevich Fet. [Afanasy Afanasyevich Fet]. Moscow, Publ. Prosveshchenie, $302 \mathrm{p}$.

20. Nikol'skiy B.V. 1912. Osnovnyye elementy liriki Feta. [The main elements of Fet's lyrics]. In: A.A. Fet. Polnoye sobraniye stikhotvoreniy. [A.A. Fet. The complete collection of poems]. Vol. 1. St. Petersburg, Edition of A.F. Marx, 603 p. $1102-1104$.

21. Nikolsky B.V. 1894. Poet filosofov. [Poet of the Philosophers]. Russkoye obozreniye, 12: 
22. Pigulevskaya I.S. 2020. Fet Afanasiy Afanas'yevich. [Fet Afanasiy Afanasyevich]. Moscow, Publ. Tsentrpoligraf, $220 \mathrm{p}$.

23. Polonskiy Ya.P. 1899. Filosofskiye techeniya russkoy poezii. Izd. 2. [Philosophical currents of Russian poetry. Ed. 2.] St. Petersburg, Publ. M. Merkusheva. 384 p.

24. Solovyov V.S. 1990. Stikhotvoreniya. Estetika. Literaturnaya kritika. [Poems. Aesthetics. Literary criticism]. Moscow, Publ. Kniga, 574 p.

25. Strakhov N.N. 1912. Yubiley poezii Feta. [Anniversary of Fet's poetry]. In: A.A. Fet. Polnoye sobraniye stikhotvoreniy. [A.A. Fet. The complete collection of poems]. Vol. 1. St. Petersburg, Edition of A.F. Marx, 603 p.

26. Strakhov N.N. 2000. Literaturnaya kritika. [Literary criticism]. St. Petersburg, Publ. Iskusstvo, $464 \mathrm{p}$.

27. Shevyrev S.P. 1844. Perevod iz Goratsiya g. A. Feta. [Translation from Horace by Mr. A. Fet]. Moskvityanin, 1 (I): 27 p.

28. Shenshina V.A. 2011. Izucheniye zhizni i tvorchestva Feta na sovremennom etape. [Studying the life and work of Fet at the present stage]. Literaturovedcheskiy zhurnal, 30: 5-17.

Конфликт интересов: о потенциальном конфликте интересов не сообщалось.

Conflict of interest: no potential conflict of interest related to this article was reported.

\section{ИНФОРМАЦИЯ ОБ АВТОРАХ}

Липич Тамара Ивановна, доктор философских наук, профессор, заведующая кафедрой философии и теологии Белгородского государственного национального исследовательского университета, г. Белгород, Россия

Липич Василий Васильевич, доктор филологических наук, профессор кафедры русского языка и русской литературы Белгородского государственного национального исследовательского университета, г. Белгород, Россия

\section{INFORMATION ABOUT THE AUTHORS}

Tamara I. Lipich, Doctor of Philosophy, Professor, Head of the Department of Philosophy and Theology Belgorod National Research University, Belgorod, Russia

Vasily V. Lipich, Doctor of Philology, Professor of the Department of Russian Language and Russian Literature Belgorod National Research University, Belgorod, Russia 